\title{
Generalized Ulam-Hyers stability and well-posedness for fixed point equation via $\alpha$-admissibility
}

\author{
Supak Phiangsungnoen and Poom Kumam* \\ Dedicated to Professor SS Chang on the occasion of his 80th birthday.
}

\author{
${ }^{*}$ Correspondence: \\ poom.kum@kmutt.ac.th \\ Department of Mathematics, \\ Faculty of Science, King Mongkut's \\ University of Technology Thonburi \\ (KMUTT), 126 Pracha Uthit Rd., Bang \\ Mod, Thung Khru, Bangkok, 10140, \\ Thailand
}

\begin{abstract}
In this paper, we extend the concept of contraction mappings in $b$-metric spaces and utilize this concept to prove the existence and uniqueness of fixed point theorems for such mappings in such a space. We also prove the generalized Ulam-Hyers stability and well-posed results for a fixed point equation employing the concept of $\alpha$-admissibility in $b$-metric spaces. We shall construct some examples to support our novel results.

MSC: $46540 ; 47540 ; 47 \mathrm{H} 10$
\end{abstract}

Keywords: $\alpha$-admissible mappings; $b$-metric space; fixed point; generalized Ulam-Hyers stability; well-posedness

\section{Introduction}

The classical Banach contraction principle is a very important tool in solving existence problems in many branches of mathematics. Over the years, it has been generalized in several different directions by several mathematicians (see [1-7]). In 1993, Czerwik [8] introduced and proved the contraction mapping principle in $b$-metric spaces that generalized the famous Banach contraction principle in such spaces. Subsequently several other authors [9-15] have studied and established the existence of fixed points of a contractive mapping in $b$-metric spaces.

The study of stability problems for various functional equations play the most important role in mathematical analysis. In the fall of 1940, Ulam [16] discussed a number of important unsolved mathematical problems. Among them, a question concerning the stability of homomorphisms seemed too abstract for anyone to reach any conclusion. In the following year, Hyers [17] gave a first affirmative partial answer to Ulam's question for Banach spaces, this type of stability is called Ulam-Hyers stability. A large number of papers have been published in connection with various generalizations of Ulam-Hyers stability results in fixed point theory and remarkable result on the stability of certain classes of functional equations via fixed point approach (see [18-29] and references therein).

On the other hand, Samet et al. [30] introduced the concepts of $\alpha$ - $\psi$-contractive mapping and $\alpha$-admissible self-mappings. Also, they proved some fixed point results for such mappings in complete metric spaces. Naturally, many authors have started to investigate 
the existence of a fixed point theorem via $\alpha$-admissible mappings for single valued and multivalued mappings (see [31-38]). Recently Bota et al. [39] considered the existence and the uniqueness of fixed point theorems and generalized Ulam-Hyers stability results via $\alpha$-admissible mappings in $b$-metric spaces.

In this paper, we extend the concept of $\alpha-\psi$-contractive mapping in $b$-metric spaces. By using this concept, we establish the existence and uniqueness of fixed point for some new types of contractive mappings in $b$-metric spaces and give an example to illustrate our main results. Moreover, we study and prove the generalized Ulam-Hyers stability and well-posed results by using fixed point method via $\alpha$-admissible mappings in $b$-metric spaces.

\section{Preliminaries}

Throughout this paper, we shall use the following notation.

Definition $2.1([40,41])$ Let $X$ be a nonempty set and the functional $d: X \times X \rightarrow[0, \infty)$ satisfy:

(b1) $d(x, y)=0$ if and only if $x=y$,

(b2) $d(x, y)=d(y, x)$ for all $x, y \in X$,

(b3) there exists a real number $s \geq 1$ such that $d(x, z) \leq s[d(x, y)+d(y, z)]$, for all $x, y, z \in X$.

Then $d$ is called a $b$-metric on $X$ and a pair $(X, d)$ is called a $b$-metric space with coefficient $s$.

Remark 2.2 If we take $s=1$ in above definition then $b$-metric spaces turns into usual metric spaces. Hence, the class of $b$-metric spaces is larger than the class of usual metric spaces.

Examples of $b$-metric spaces were given in $[8,40-43]$.

Example 2.3 The set $l_{p}(\mathbb{R})$ with $0<p<1$, where $l_{p}(\mathbb{R}):=\left\{\left.\left\{x_{n}\right\} \subset \mathbb{R}\left|\sum_{n=1}^{\infty}\right| x_{n}\right|^{p}<\infty\right\}$, together with the functional $d: l_{p}(\mathbb{R}) \times l_{p}(\mathbb{R}) \rightarrow[0, \infty)$,

$$
d(x, y):=\left(\sum_{n=1}^{\infty}\left|x_{n}-y_{n}\right|^{p}\right)^{\frac{1}{p}}
$$

(where $x=\left\{x_{n}\right\}, y=\left\{y_{n}\right\} \in l_{p}(\mathbb{R})$ ) is a $b$-metric spaces with coefficient $s=2^{\frac{1}{p}}>1$. Notice that the above result holds for the general case $l_{p}(X)$ with $0<p<1$, where $X$ is a Banach spaces.

Example 2.4 Let $X$ be a set with the cardinal $\operatorname{card}(X) \geq 3$. Suppose that $X=X_{1} \cup X_{2}$ is a partition of $X$ such that $\operatorname{card}\left(X_{1}\right) \geq 2$. Let $s>1$ be arbitrary. Then the functional $d: X \times$ $X \rightarrow[0, \infty)$ defined by

$$
d(x, y):= \begin{cases}0, & x=y \\ 2 s, & x, y \in X_{1}, \\ 1, & \text { otherwise }\end{cases}
$$

is a $b$-metric on $X$ with coefficient $s>1$. 
Definition 2.5 ([42]) Let $(X, d)$ be a $b$-metric spaces. Then a sequence $\left\{x_{n}\right\}$ in $X$ is called

(a) convergent if and only if there exists $x \in X$ such that $d\left(x_{n}, x\right) \rightarrow 0$ as $n \rightarrow \infty$;

(b) Cauchy if and only if $d\left(x_{n}, x_{m}\right) \rightarrow 0$ as $m, n \rightarrow \infty$.

Lemma $2.6([41])$ Let $(X, d)$ be a b-metric spaces and let $\left\{x_{k}\right\}_{k=0}^{n} \subset X$. Then

$$
d\left(x_{0}, x_{n}\right) \leq s d\left(x_{0}, x_{1}\right)+\cdots+s^{n-1} d\left(x_{n-2}, x_{n-1}\right)+s^{n} d\left(x_{n-1}, x_{n}\right) .
$$

Definition 2.7 ([21]) A mapping $\psi:[0, \infty) \rightarrow[0, \infty)$ is called a comparison function if it is increasing and $\psi^{n}(t) \rightarrow 0$ as $n \rightarrow \infty$, for any $t \in[0, \infty)$.

Lemma $2.8([21,44])$ If $\psi:[0, \infty) \rightarrow[0, \infty)$ is a comparison function, then

(1) $\psi^{n}$ is also a comparison function, where $\psi^{n}$ is nth iterate of $\psi$;

(2) $\psi$ is continuous at 0 ;

(3) $\psi(t)<t$, for any $t>0$.

The concept of $(c)$-comparison function was introduced by Berinde [44] in the following definition.

Definition 2.9 A function $\psi:[0, \infty) \rightarrow[0, \infty)$ is said to be a $(c)$-comparison function if

(1) $\psi$ is increasing;

(2) there exist $n_{0} \in \mathbb{N}, k \in(0,1)$ and a convergent series of nonnegative terms $\sum_{n=1}^{\infty} \epsilon_{n}$ such that $\psi^{n+1}(t) \leq k \psi^{n}(t)+\epsilon_{n}$, for $n \geq n_{0}$ and any $t \in[0, \infty)$.

Here we recall the definitions of the following class of $(b)$-comparison function as given by Berinde [45] in order to extend some fixed point results to the class of $b$-metric spaces.

Definition 2.10 ([45]) Let $s \geq 1$ be a real number. A mapping $\psi:[0, \infty) \rightarrow[0, \infty)$ is called a (b)-comparison function if the following conditions are fulfilled:

(1) $\psi$ is increasing;

(2) there exist $n_{0} \in \mathbb{N}, k \in(0,1)$, and a convergent series of nonnegative terms $\sum_{n=1}^{\infty} \epsilon_{n}$ such that $s^{n+1} \psi^{n+1}(t) \leq k s^{n} \psi^{n}(t)+\epsilon_{n}$, for $n \geq n_{0}$ and any $t \in[0, \infty)$.

In this work, we denote by $\Psi_{b}$ the class of (b)-comparison function $\psi:[0, \infty) \rightarrow[0, \infty)$. It is evident that the concept of $(b)$-comparison function reduces to that of $(c)$-comparison function when $s=1$.

Lemma $2.11([43])$ If $\psi:[0, \infty) \rightarrow[0, \infty)$ is a (b)-comparison function, then we have the following:

(i) the series $\sum_{n=0}^{\infty} s^{n} \psi^{n}(t)$ converges for any $t \in[0, \infty)$;

(ii) the function $S:[0, \infty) \rightarrow[0, \infty)$, defined by $S(t)=\sum_{n=0}^{\infty} s^{n} \psi^{n}(t), t \in[0, \infty)$, is increasing and continuous at 0 .

Next, we will present the concept of $\alpha$-admissible mappings introduced by Samet et al. [30].

Definition 2.12 ([30]) Let $X$ be a nonempty set, $f: X \rightarrow X$ and $\alpha: X \times X \rightarrow[0, \infty)$. We say that $f$ is an $\alpha$-admissible mapping if it satisfies the following condition:

$$
\text { for } x, y \in X \text { for which } \alpha(x, y) \geq 1 \quad \Longrightarrow \quad \alpha(f(x), f(y)) \geq 1 .
$$


Example 2.13 Let $X=(0, \infty)$. Define $f: X \rightarrow X$ and $\alpha: X \times X \rightarrow[0, \infty)$ by

$$
f(x)=\sinh (x) \quad \text { for all } x \in X
$$

and

$$
\alpha(x, y)= \begin{cases}\frac{x+y+1}{|x-y|+1}, & \text { if } x \geq y, \\ 0, & \text { if } x<y .\end{cases}
$$

Then $f$ is $\alpha$-admissible.

Example 2.14 Let $X=\mathbb{R}$. Define $f: X \rightarrow X$ and $\alpha: X \times X \rightarrow[0, \infty)$ by

$$
f(x)= \begin{cases}\cosh (2 x+1), & \text { if } x>1 \\ 1-\frac{1}{2^{|x|}}, & \text { if } 0 \leq x \leq 1 \\ 0, & \text { otherwise }\end{cases}
$$

and

$$
\alpha(x, y)= \begin{cases}1, & \text { if } x, y \in[0,1] \\ 0, & \text { otherwise }\end{cases}
$$

Then $f$ is $\alpha$-admissible.

\section{Fixed point theorems for $\alpha$-admissible mapping in $b$-metric spaces}

In this section, we prove the existence and uniqueness of fixed point theorems in a $b$-metric space.

Definition 3.1 Let $(X, d)$ be a $b$-metric space with coefficient $s$. A mapping $f: X \rightarrow X$ is said to be a generalized $\alpha$ - $\psi$-contraction in $b$-metric space if there exist functions $\psi \in \Psi_{b}$ and $\alpha: X \times X \rightarrow[0, \infty)$ such that the following condition holds:

$$
\text { for } x, y \in X \text { with } \alpha(x, f(x)) \alpha(y, f(y)) \geq 1 \quad \Longrightarrow \quad d(f(x), f(y)) \leq \psi(d(x, y)) \text {. }
$$

Theorem 3.2 Let $(X, d)$ be a complete b-metric space with coefficient $s$ and $f$ be a generalized $\alpha-\psi$-contraction. Suppose that the following conditions hold:

(a) $f$ is an $\alpha$-admissible;

(b) there exists $x_{0} \in X$ such that $\alpha\left(x_{0}, f\left(x_{0}\right)\right) \geq 1$;

(c) if $\left\{x_{n}\right\}$ is sequence in $X$ such that $x_{n} \rightarrow x$ as $n \rightarrow \infty$ and $\alpha\left(x_{n}, f\left(x_{n}\right)\right) \geq 1$ for all $n \in \mathbb{N}$, then $\alpha(x, f(x)) \geq 1$.

Then $f$ has a unique fixed point $x^{*}$ in $X$ such that $\alpha\left(x^{*}, f\left(x^{*}\right)\right) \geq 1$.

Proof Let $x_{0} \in X$ such that $\alpha\left(x_{0}, f\left(x_{0}\right)\right) \geq 1$ (from condition (b)). We define the sequence $\left\{x_{n}\right\}$ in $X$ such that

$$
x_{n}=f\left(x_{n-1}\right) \quad \text { for all } n \in \mathbb{N} \text {. }
$$


Since $f$ is an $\alpha$-admissible and

$$
\alpha\left(x_{0}, x_{1}\right)=\alpha\left(x_{0}, f\left(x_{0}\right)\right) \geq 1
$$

we deduce that

$$
\alpha\left(x_{1}, f\left(x_{1}\right)\right)=\alpha\left(f\left(x_{0}\right), f\left(x_{1}\right)\right) \geq 1 .
$$

By continuing this process, we get $\alpha\left(x_{n-1}, f\left(x_{n-1}\right)\right) \geq 1$ for all $n \in \mathbb{N}$. This implies that

$$
\alpha\left(x_{n-1}, f\left(x_{n-1}\right)\right) \alpha\left(x_{n}, f\left(x_{n}\right)\right) \geq 1
$$

for all $n \in \mathbb{N}$. From (3.1), we obtain

$$
d\left(x_{n}, x_{n+1}\right)=d\left(f\left(x_{n-1}\right), f\left(x_{n}\right)\right) \leq \psi\left(d\left(x_{n-1}, x_{n}\right)\right)
$$

for all $n \in \mathbb{N}$. By repeating the above process, we get

$$
d\left(x_{n}, x_{n+1}\right) \leq \psi^{n}\left(d\left(x_{0}, x_{1}\right)\right)
$$

for all $n \in \mathbb{N}$. Next, we show that $\left\{x_{n}\right\}$ is a Cauchy sequence in $X$. For $m, n \in \mathbb{N}$ with $m>n$, we have

$$
\begin{aligned}
d\left(x_{n}, x_{m}\right) \leq & s d\left(x_{n}, x_{n+1}\right)+s^{2} d\left(x_{n+1}, x_{n+2}\right)+\cdots+s^{m-n-2} d\left(x_{m-3}, x_{m-2}\right) \\
& +s^{m-n-1} d\left(x_{m-2}, x_{m-1}\right)+s^{m-n} d\left(x_{m-1}, x_{m}\right) \\
\leq & s \psi^{n}\left(d\left(x_{0}, x_{1}\right)\right)+s^{2} \psi^{n+1}\left(d\left(x_{0}, x_{1}\right)\right)+\cdots+s^{m-n-2} \psi^{m-3}\left(d\left(x_{0}, x_{1}\right)\right) \\
& +s^{m-n-1} \psi^{m-2}\left(d\left(x_{0}, x_{1}\right)\right)+s^{m-n} \psi^{m-1}\left(d\left(x_{0}, x_{1}\right)\right) \\
= & \frac{1}{s^{n-1}}\left[s^{n} \psi^{n}\left(d\left(x_{0}, x_{1}\right)\right)+s^{n+1} \psi^{n+1}\left(d\left(x_{0}, x_{1}\right)\right)+\cdots+s^{m-2} \psi^{m-2}\left(d\left(x_{0}, x_{1}\right)\right)\right. \\
& \left.+s^{m-1} \psi^{m-1}\left(d\left(x_{0}, x_{1}\right)\right)\right] .
\end{aligned}
$$

Denote $S_{n}=\sum_{i=0}^{n} s^{i} \psi^{i}\left(d\left(x_{0}, x_{1}\right)\right)$ for all $n \in \mathbb{N}$. This implies that

$$
d\left(x_{n}, x_{m}\right) \leq \frac{1}{s^{n-1}}\left[S_{m-1}-S_{n-1}\right] \text { for all } n, m \in \mathbb{N}
$$

By Lemma 2.11 we know that the series $\sum_{i=0}^{\infty} s^{i} \psi^{i}\left(d\left(x_{0}, x_{1}\right)\right)$ converges. Therefore, $\left\{x_{n}\right\}$ is Cauchy sequence in $X$. By the completeness of $X$, there exists $x^{*} \in X$ such that $x_{n} \rightarrow x^{*}$ as $n \rightarrow \infty$. Using condition (c), we get $\alpha\left(x^{*}, f\left(x^{*}\right)\right) \geq 1$. Also, we have $\alpha\left(x_{n-1}, f\left(x_{n-1}\right)\right) \alpha\left(x^{*}\right.$, $\left.f\left(x^{*}\right)\right) \geq 1$ for all $n \in \mathbb{N}$. From the assumption (3.1), we have

$$
\begin{aligned}
d\left(f\left(x^{*}\right), x^{*}\right) & \leq s\left[d\left(f\left(x^{*}\right), x_{n}\right)+d\left(x_{n}, x^{*}\right)\right] \\
& =s\left[d\left(f\left(x^{*}\right), f\left(x_{n-1}\right)\right)+d\left(x_{n}, x^{*}\right)\right] \\
& \leq s\left[\psi\left(d\left(x^{*}, x_{n-1}\right)\right)+d\left(x_{n}, x^{*}\right)\right] .
\end{aligned}
$$


Letting $n \rightarrow \infty$, it follows that $d\left(f\left(x^{*}\right), x^{*}\right)=0$, that is, $x^{*}$ is a fixed point of $f$ such that $\alpha\left(x^{*}, f\left(x^{*}\right)\right) \geq 1$.

Next, we prove the uniqueness of the fixed point of $f$. Let $y^{*}$ be another fixed point of $f$ such that

$$
\alpha\left(y^{*}, f\left(y^{*}\right)\right) \geq 1
$$

Therefore, we get

$$
\alpha\left(x^{*}, f\left(x^{*}\right)\right) \alpha\left(y^{*}, f\left(y^{*}\right)\right) \geq 1 .
$$

It follows that

$$
d\left(x^{*}, y^{*}\right)=d\left(f\left(x^{*}\right), f\left(y^{*}\right)\right)<d\left(x^{*}, y^{*}\right)
$$

which is a contradiction. Therefore, $x^{*}$ is the unique fixed point of $f$ such that $\alpha\left(x^{*}\right.$, $\left.f\left(x^{*}\right)\right) \geq 1$. This completes the proof.

In view of Theorem 3.2, we have the following corollary.

Corollary 3.3 Let $(X, d)$ be a complete b-metric space with coefficient $s, f: X \rightarrow X, \alpha$ : $X \times X \rightarrow[0, \infty)$, and $\psi \in \Psi_{b}$ be three mappings. Suppose that the following conditions hold:

(a) $f$ is an $\alpha$-admissible;

(b) there exists $x_{0} \in X$ such that $\alpha\left(x_{0}, f\left(x_{0}\right)\right) \geq 1$;

(c) if $\left\{x_{n}\right\}$ is sequence in $X$ such that $x_{n} \rightarrow x$ as $n \rightarrow \infty$ and $\alpha\left(x_{n}, f\left(x_{n}\right)\right) \geq 1$ for all $n \in \mathbb{N}$, then $\alpha(x, f(x)) \geq 1$;

(d) $f$ satisfies the following condition:

$$
\alpha(x, f(x)) \alpha(y, f(y)) d(f(x), f(y)) \leq \psi(d(x, y))
$$

for all $x, y \in X$.

Then $f$ has a unique fixed point $x^{*}$ in $X$ such that $\alpha\left(x^{*}, f\left(x^{*}\right)\right) \geq 1$.

Corollary 3.4 Let $(X, d)$ be a complete b-metric space with coefficient $s, f: X \rightarrow X, \alpha$ : $X \times X \rightarrow[0, \infty)$, and $\psi \in \Psi_{b}$ be three mappings. Suppose that the following conditions hold:

(a) $f$ is an $\alpha$-admissible;

(b) there exists $x_{0} \in X$ such that $\alpha\left(x_{0}, f\left(x_{0}\right)\right) \geq 1$;

(c) if $\left\{x_{n}\right\}$ is sequence in $X$ such that $x_{n} \rightarrow x$ as $n \rightarrow \infty$ and $\alpha\left(x_{n}, f\left(x_{n}\right)\right) \geq 1$ for all $n \in \mathbb{N}$, then $\alpha(x, f(x)) \geq 1$;

(d) $f$ satisfies the following condition:

$$
[d(f(x), f(y))+\xi]^{\alpha(x, f(x)) \alpha(y, f(y))} \leq \psi(d(x, y))+\frac{\xi}{S}
$$

for all $x, y \in X$, where $\xi \geq 1$.

Then $f$ has a unique fixed point $x^{*}$ in $X$ such that $\alpha\left(x^{*}, f\left(x^{*}\right)\right) \geq 1$. 
Corollary 3.5 Let $(X, d)$ be a complete b-metric space with coefficient $s, f: X \rightarrow X, \alpha$ : $X \times X \rightarrow[0, \infty)$, and $\psi \in \Psi_{b}$ be three mappings. Suppose that the following conditions hold:

(a) $f$ is an $\alpha$-admissible;

(b) there exists $x_{0} \in X$ such that $\alpha\left(x_{0}, f\left(x_{0}\right)\right) \geq 1$;

(c) if $\left\{x_{n}\right\}$ is sequence in $X$ such that $x_{n} \rightarrow x$ as $n \rightarrow \infty$ and $\alpha\left(x_{n}, f\left(x_{n}\right)\right) \geq 1$ for all $n \in \mathbb{N}$, then $\alpha(x, f(x)) \geq 1$;

(d) $f$ satisfies the following condition:

$$
(\alpha(x, f(x)) \alpha(y, f(y))-1+\xi)^{d(f(x), f(y))} \leq \xi^{\psi(d(x, y))}
$$

for all $x, y \in X$, where $\xi>1$.

Then $f$ has a unique fixed point $x^{*}$ in $X$ such that $\alpha\left(x^{*}, f\left(x^{*}\right)\right) \geq 1$.

If we set $\alpha(x, y)=1$ for all $x, y \in X$ in Theorem 3.2, we get the following results.

Corollary 3.6 Let $(X, d)$ be a complete b-metric space with coefficient $s$ and $f: X \rightarrow X$ be a mapping. Suppose that $f$ satisfies

$$
d(f(x), f(y)) \leq \psi(d(x, y))
$$

for all $x, y \in X$, where $\psi \in \Psi_{b}$. Then $f$ has a unique fixed point in $X$.

If the coefficient $s=1$ in Corollary 3.6, we immediately get the following result.

Corollary $3.7[46]$ Let $(X, d)$ be a complete metric space and $\psi:[0, \infty) \rightarrow[0, \infty)$ be (c)-comparison function. Suppose that $f: X \rightarrow X$ be a mapping satisfies

$$
d(f(x), f(y)) \leq \psi(d(x, y))
$$

for all $x, y \in X$. Then $f$ has a unique fixed point in $X$.

Remark 3.8 If $\psi(t)=k t$, where $k \in(0,1)$ in Corollary 3.7, we get the Banach contraction principle.

Next, we give an example showing that the contractive conditions in our results are independent. Also, our results are real generalizations of the Banach contraction principle in $b$-metric spaces and several results in literature.

Example 3.9 Let $X=[0, \infty)$ and $d(x, y)=|x-y|^{2}$ for all $x, y \in X$. Then $d$ is a complete $b$-metric space on $X$ with coefficient $s=2$. Define $f: X \rightarrow X$ by

$$
f(x)= \begin{cases}0.2, & x=0, \\ \frac{4 x}{\cosh x}, & x \in(0,1), \\ \frac{x+1}{2}, & {[1, \infty)}\end{cases}
$$


Also, define $\alpha: X \times X \rightarrow[0, \infty)$ and $\psi:[0, \infty) \rightarrow[0, \infty)$ by

$$
\alpha(x, y)= \begin{cases}0, & x, y \in[0,1), \\ 1, & x, y \in[1, \infty),\end{cases}
$$

and $\psi(t)=\frac{1}{2} t$ for all $t \geq 0$.

Now, we show that $f$ is a generalized $\alpha$ - $\psi$-contraction mapping. For $x, y \in X$ with

$$
\alpha(x, f(x)) \alpha(y, f(y)) \geq 1,
$$

we get $x, y \in[1, \infty)$. Then we have

$$
\begin{aligned}
d(f(x), f(y)) & =\left|\frac{x+1}{2}-\frac{y+1}{2}\right|^{2} \\
& =\frac{1}{4}|x-y|^{2} \\
& \leq \frac{1}{2} d(x, y) \\
& =\psi(d(x, y)) .
\end{aligned}
$$

It is easy to see that $f$ is an $\alpha$-admissible mapping. There exists $x_{0}=2 \in X$ such that

$$
\alpha\left(x_{0}, f\left(x_{0}\right)\right)=\alpha(2, f(2))=\alpha(2,1.5)=2 \geq 1 .
$$

Also, we can easily to prove that condition (c) in Theorem 3.2 holds. Therefore, all of conditions in Theorem 3.2 hold. In this example, we have 1 is a unique fixed point of $f$ and $\alpha(1, f(1)) \geq 1$.

Remark 3.10 We observe that the contractive condition in Corollary 3.4 cannot be applied to this example. Indeed, for $x=1$ and $y=2$, we obtain

$$
[d(f(x), f(y))+\xi]^{\alpha(x, f(x)) \alpha(y, f(y))}>\psi(d(x, y))+\frac{\xi}{s},
$$

where $\xi=1$ and $s=2$. Therefore, Corollary 3.4 cannot be applied to this case. Also, by a similar method, we can show that Corollary 3.5 cannot be applied to this case.

Also, we can see that the fixed point result for Banach contraction principle in $b$-metric spaces cannot be applied to this case. Indeed, for $x=0.4$ and $y=0.5$, we get

$$
d(f(x), f(y))=\left|\frac{4(0.4)}{\cosh 0.4}-\frac{4(0.5)}{\cosh 0.5}\right|^{2}>0.07>0.01=|0.4-0.5|^{2}=d(x, y) .
$$

\section{The generalized Ulam-Hyers stability in $\boldsymbol{b}$-metric spaces}

In this section, we prove the generalized Ulam-Hyers stability in $b$-metric spaces for which Theorem 3.2 holds.

Let $(X, d)$ be a $b$-metric spaces with coefficient $s$ and $f: X \rightarrow X$ be an operator. Let us consider the fixed point equation

$$
x=f(x), \quad x \in X
$$


and the inequality

$$
d(v, f(v)) \leq \varepsilon, \quad \text { where } \varepsilon>0 .
$$

Theorem 4.1 Let $(X, d)$ be a complete b-metric space with coefficient s. Suppose that all the hypotheses of Theorem 3.2 hold and also that the function $\varphi:[0, \infty) \rightarrow[0, \infty)$ defined by $\varphi(t):=t-s \psi(t)$ is strictly increasing and onto. If $\alpha\left(u^{*}, f\left(u^{*}\right)\right) \geq 1$ for all $u^{*} \in X$ which is an $\varepsilon$-solution, then the fixed point equation (4.1) is generalized Ulam-Hyers stable.

Proof By Theorem 3.2, we have $f\left(x^{*}\right)=x^{*}$, that is, $x^{*} \in X$ is a solution of the fixed point equation (4.1). Let $\varepsilon>0$ and $y^{*} \in X$ is an $\varepsilon$-solution, that is,

$$
d\left(y^{*}, f\left(y^{*}\right)\right) \leq \varepsilon
$$

Since $x^{*}, y^{*} \in X$ are $\varepsilon$-solution, we have

$$
\alpha\left(x^{*}, f\left(x^{*}\right)\right) \geq 1 \quad \text { and } \quad \alpha\left(y^{*}, f\left(y^{*}\right)\right) \geq 1 .
$$

Also, we have

$$
\alpha\left(x^{*}, f\left(x^{*}\right)\right) \alpha\left(y^{*}, f\left(y^{*}\right)\right) \geq 1 .
$$

Now, we obtain

$$
\begin{aligned}
d\left(x^{*}, y^{*}\right) & =d\left(f\left(x^{*}\right), y^{*}\right) \\
& \leq s\left[d\left(f\left(x^{*}\right), f\left(y^{*}\right)\right)+d\left(f\left(y^{*}\right), y^{*}\right)\right] \\
& \leq s\left[\psi\left(d\left(x^{*}, y^{*}\right)\right)+d\left(f\left(y^{*}\right), y^{*}\right)\right] \\
& \leq s \psi\left(d\left(x^{*}, y^{*}\right)\right)+s \varepsilon .
\end{aligned}
$$

It follows that

$$
d\left(x^{*}, y^{*}\right)-s\left(\psi\left(d\left(x^{*}, y^{*}\right)\right)\right) \leq s \varepsilon .
$$

Since $\varphi(t):=t-s \psi(t)$, we have

$$
\varphi\left(d\left(x^{*}, y^{*}\right)\right)=d\left(x^{*}, y^{*}\right)-s \psi\left(d\left(x^{*}, y^{*}\right)\right) .
$$

It implies that

$$
d\left(x^{*}, y^{*}\right) \leq \varphi^{-1}(s \varepsilon) .
$$

Notice that $\varphi^{-1}:[0, \infty) \rightarrow[0, \infty)$ exists, is increasing, continuous at 0 and $\varphi^{-1}(0)=0$. Therefore, the fixed point equation (4.1) is generalized Ulam-Hyers stable.

Corollary 4.2 Let $(X, d)$ be a complete b-metric space with coefficient s. Suppose that all the hypotheses of Corollary 3.3 hold and also that the function $\varphi:[0, \infty) \rightarrow[0, \infty)$ defined 
by $\varphi(t):=t-s \psi(t)$ is strictly increasing and onto. If $\alpha\left(u^{*}, f\left(u^{*}\right)\right) \geq 1$ for all $u^{*} \in X$ which is an $\varepsilon$-solution, then the fixed point equation (4.1) is generalized Ulam-Hyers stable.

Corollary 4.3 Let $(X, d)$ be a complete b-metric space with coefficient s. Suppose that all the hypotheses of Corollary 3.4 hold and also that the function $\varphi:[0, \infty) \rightarrow[0, \infty)$ defined by $\varphi(t):=t-s \psi(t)$ is strictly increasing and onto. If $\alpha\left(u^{*}, f\left(u^{*}\right)\right) \geq 1$ for all $u^{*} \in X$ which is an $\varepsilon$-solution, then the fixed point equation (4.1) is generalized Ulam-Hyers stable.

Corollary 4.4 Let $(X, d)$ be a complete b-metric space with coefficient s. Suppose that all the hypotheses of Corollary 3.5 hold and also that the function $\varphi:[0, \infty) \rightarrow[0, \infty)$ defined by $\varphi(t):=t-s \psi(t)$ is strictly increasing and onto. If $\alpha\left(u^{*}, f\left(u^{*}\right)\right) \geq 1$ for all $u^{*} \in X$ which is an $\varepsilon$-solution, then the fixed point equation (4.1) is generalized Ulam-Hyers stable.

\section{Well-posedness of a function with respect to $\alpha$-admissibility in $b$-metric spaces}

In this section, we present and prove well-posedness of a function with respect to an $\alpha$-admissible mapping in $b$-metric spaces.

Definition 5.1 Let $(X, d)$ be a complete $b$-metric spaces with coefficient $s$ and $f: X \rightarrow X$, $\alpha: X \times X \rightarrow[0, \infty)$. The fixed point problem of $f$ is said to be well-posed with respect to $\alpha$ if

(i) $f$ has a unique fixed point $x^{*}$ in $X$ such that $\alpha\left(x^{*}, f\left(x^{*}\right)\right) \geq 1$;

(ii) for sequence $\left\{x_{n}\right\}$ in $X$ such that $d\left(x_{n}, f\left(x_{n}\right)\right) \rightarrow 0$, as $n \rightarrow \infty$, then $x_{n} \rightarrow x^{*}$, as $n \rightarrow \infty$

In the following next theorems, we add a new condition to assure the well-posedness via $\alpha$-admissibility.

(S) If $\left\{x_{n}\right\}$ is sequence in $X$ such that $d\left(x_{n}, f\left(x_{n}\right)\right) \rightarrow 0$, as $n \rightarrow \infty$, then $\alpha\left(x_{n}, f\left(x_{n}\right)\right) \geq 1$ for all $n \in \mathbb{N}$.

Theorem 5.2 Let $(X, d)$ be a complete b-metric space with coefficient $s, f: X \rightarrow X, \alpha$ : $X \times X \rightarrow[0, \infty)$, and $\psi \in \Psi_{b}$. Suppose that all the hypotheses of Theorem 3.2 and condition (S) hold. Then the fixed point equation (4.1) is well-posed with respect to $\alpha$.

Proof By Theorem 3.2, there unique exists $x^{*} \in X$ such that $f\left(x^{*}\right)=x^{*}$ and $\alpha\left(x^{*}, f\left(x^{*}\right)\right) \geq 1$. Let $\left\{x_{n}\right\}$ be sequence in $X$ such that $d\left(x_{n}, f\left(x_{n}\right)\right) \rightarrow 0$, as $n \rightarrow \infty$. By condition (S), we get

$$
\alpha\left(x_{n}, f\left(x_{n}\right)\right) \geq 1 .
$$

Also, we get

$$
\alpha\left(x_{n}, f\left(x_{n}\right)\right) \alpha\left(x^{*}, f\left(x^{*}\right)\right) \geq 1 .
$$

Now, we have

$$
\begin{aligned}
d\left(x_{n}, x^{*}\right) & =d\left(x_{n}, f\left(x^{*}\right)\right) \\
& \leq s\left[d\left(x_{n}, f\left(x_{n}\right)\right)+d\left(f\left(x_{n}\right), f\left(x^{*}\right)\right)\right] \\
& \leq s\left[\psi\left(d\left(x_{n}, x^{*}\right)\right)+d\left(x_{n}, f\left(x_{n}\right)\right)\right] .
\end{aligned}
$$


$\psi$ is continuous at 0 and $d\left(x_{n}, f\left(x_{n}\right)\right) \rightarrow 0$ as $n \rightarrow \infty$. It implies that $d\left(x_{n}, x^{*}\right) \rightarrow 0$ as $n \rightarrow$ $\infty$, that is, $x_{n} \rightarrow x^{*}$, as $n \rightarrow \infty$. Therefore, the fixed point equation (4.1) is well-posed with respect to $\alpha$.

Corollary 5.3 Let $(X, d)$ be a complete $b$-metric space with coefficient $s, f: X \rightarrow X, \alpha: X \times$ $X \rightarrow[0, \infty)$, and $\psi \in \Psi_{b}$. Suppose that all the hypotheses of Corollary 3.3 and condition (S) hold. Then the fixed point equation (4.1) is well-posed with respect to $\alpha$.

Corollary 5.4 Let $(X, d)$ be a complete $b$-metric space with coefficient $s, f: X \rightarrow X, \alpha: X \times$ $X \rightarrow[0, \infty)$, and $\psi \in \Psi_{b}$. Suppose that all the hypotheses of Corollary 3.4 and condition (S) hold. Then the fixed point equation (4.1) is well-posed with respect to $\alpha$.

Corollary 5.5 Let $(X, d)$ be a complete $b$-metric space with coefficient $s, f: X \rightarrow X, \alpha$ : $X \times X \rightarrow[0, \infty)$, and $\psi \in \Psi_{b}$. Suppose that all the hypotheses of Corollary 3.5 and condition (S) hold. Then the fixed point equation (4.1) is well-posed with respect to $\alpha$.

\section{Competing interests}

The authors declare that they have no competing interests.

\section{Authors' contributions}

All authors contributed equally and significantly in writing this paper. All authors read and approved the final manuscript.

\section{Acknowledgements}

The authors were supported by the Higher Education Research Promotion and National Research University Project of Thailand, Office of the Higher Education Commission (NRU57000621). Moreover, the authors are grateful Dr. Wutiphol Sintunavarat and the reviewers for careful reading of the paper and for the suggestion, which improved the quality of this work.

Received: 4 June 2014 Accepted: 30 September 2014 Published: 21 October 2014

\section{References}

1. Radenović, S, Kadelburg, Z: Quasi-contractions on symmetric and cone symmetric spaces. Banach J. Math. Anal. 5, 38-50 (2011)

2. Van An, T, Van Dung, N, Kadelburg, Z, Radenović, S: Various generalizations of metric spaces and fixed point theorems. Rev. R. Acad. Cienc. Exactas Fís. Nat., Ser. A Mat. (2014). doi:10.1007/s13398-014-0173-7

3. Agarwal, RP, Kadelburg, Z, Radenović, S: On coupled fixed point results in asymmetric G-metric spaces. J. Inequal. Appl. 2013, 528 (2013)

4. Xu, S, Radenović, S: Fixed point theorems of generalized Lipschitz mappings on cone metric spaces with Banach algebra without assumption of normality. Fixed Point Theory Appl. 2014, 102 (2014)

5. Jovanović, M, Kadelburg, Z, Radenović, S: Common fixed point results in metric-type spaces. Fixed Point Theory Appl. 2010, Article ID 978121 (2010). doi:10.1155/2010/978121

6. Ćojbašić, V, Radenović, S, Chauhan, S: Common fixed point of generalized weakly contractive maps in 0-complete partial metric spaces. Acta Math. Sci. Ser. B 34(4), 1345-1356 (2014)

7. Shah, MH, Simić, S, Hussain, N, Sretenović, A, Radenović, S: Common fixed points theorems for occasionally weakly compatible pairs on cone metric type spaces. J. Comput. Anal. Appl. 14(2), 290-297 (2012)

8. Czerwik, S: Contraction mappings in b-metric spaces. Acta Math. Inform. Univ. Ostrav. 1, 5-11 (1993)

9. Roshan, JR, Shobkolaei, N, Sedghi, S, Parvaneh, V, Radenović, S: Common fixed point theorems for three maps in discontinuous $G_{B}$-metric spaces. Acta Math. Sci. Ser. B 34(5), 1-12 (2014)

10. Azam, A, Mehmood, N, Ahmad, J, Radenović, S: Multivalued fixed point theorems in cone $b$-metric spaces. J. Inequal. Appl. 2013, $582(2013)$

11. Parvaneh, V, Roshan, JR, Radenović, S: Existence of tripled coincidence point in ordered $b$-metric spaces and applications to a system of integral equations. Fixed Point Theory Appl. 2013, 130 (2013)

12. Hussain, N, Dorić, D, Kadelburg, Z, Radenovć, S: Suzuki-type fixed point results in metric type spaces. Fixed Point Theory Appl. 2012, 126 (2012)

13. Popović, B, Radenović, S, Shukla, S: Fixed point results to tvs-cone b-metric spaces. Gulf J. Math. 1, 51-64 (2013)

14. George, R, Radenović, S, Reshma, KP, Shukla, S: Rectangular b-metric spaces and contraction principle. J. Nonlinear Sci. Appl. (2014, in press)

15. Sintunavarat, W, Plubtieng, S, Katchang, P: Fixed point result and applications on b-metric space endowed with an arbitrary binary relation. Fixed Point Theory Appl. 2013, 296 (2013)

16. Ulam, SM: Problems in Modern Mathematics. Wiley, New York (1964)

17. Hyers, DH: On the stability of the linear functional equation. Proc. Natl. Acad. Sci. USA 27(4), 222-224 (1941) 
18. Bota-Boriceanu, MF, Petruşel, A: Ulam-Hyers stability for operatorial equations. An. Ştiinţ. Univ. 'Al.I. Cuza' laşi, Mat. 57, 65-74 (2011)

19. Lazăr, VL: Ulam-Hyers stability for partial differential inclusions. Electron. J. Qual. Theory Differ. Equ. 2012,21 (2012)

20. Rus, IA: The theory of a metrical fixed point theorem: theoretical and applicative relevances. Fixed Point Theory 9(2), 541-559 (2008)

21. Rus, IA: Generalized Contractions and Applications. Cluj University Press, Cluj-Napoca (2001)

22. Rus, IA: Remarks on Ulam stability of the operatorial equations. Fixed Point Theory 10(2), 305-320 (2009)

23. Tişe, FA, Tişe, IC: Ulam-Hyers-Rassias stability for set integral equations. Fixed Point Theory 13(2), $659-668$ (2012)

24. Brzdek, J, Chudziak, J, Pales, Z: A fixed point approach to stability of functional equations. Nonlinear Anal. TMA 74, 6728-6732 (2011)

25. Brzdek, J, Cieplinski, K: A fixed point approach to the stability of functional equations in non-Archimedean metric spaces. Nonlinear Anal. TMA 74, 6861-6867 (2011)

26. Brzdek, J, Cieplinski, K: A fixed point theorem and the Hyers-Ulam stability in non-Archimedean spaces. J. Math. Anal. Appl. 400, 68-75 (2013)

27. Cadariu, L, Gavruta, L, Gavruta, P: Fixed points and generalized Hyers-Ulam stability. Abstr. Appl. Anal. 2012, Article ID $712743(2012)$

28. Sintunavarat, W: Generalized Ulam-Hyers stability, well-posedness and limit shadowing of fixed point problems for $\alpha$ - $\beta$-contraction mapping in metric spaces. Sci. World J. 2014, Article ID 569174 (2014)

29. Kutbi, MA, Sintunavarat, W: Ulam-Hyers stability and well-posedness of fixed point problems for $\alpha$ - $\lambda$-contraction mapping in metric spaces. Abstr. Appl. Anal. 2014, Article ID 268230 (2014)

30. Samet, B, Vetro, C, Vetro, P: Fixed point theorems for $\alpha$ - $\psi$-contractive type mappings. Nonlinear Anal. 75, 2154-2165 (2012)

31. Asl, JH, Rezapour, S, Shahzad, N: On fixed points of $\alpha-\psi$-contractive multifunctions. Fixed Point Theory Appl. 2012, $212(2012)$

32. Mohammadi, B, Rezapour, S, Shahzad, N: Some results on fixed points of $\alpha$ - $\psi$-Ciric generalized multifunctions. Fixed Point Theory Appl. 2013, 24 (2013)

33. Karapınar, E, Samet, B: Generalized $\alpha$ - $\psi$-contractive type mappings and related fixed point theorems with applications. Abstr. Appl. Anal. 2012, Article ID 793486 (2012)

34. Agarwal, RP, Sintunavarat, W, Kumam, P: PPF dependent fixed point theorems for an $\alpha_{c}$-admissible non-self mapping in the Razumikhin class. Fixed Point Theory Appl. 2013, 280 (2013)

35. Long, W, Khaleghizadeh, S, Salimi, P, Radenović, S, Shukla, S: Some new fixed point results in partial ordered metric spaces via admissible mappings. Fixed Point Theory Appl. 2014, 117 (2014)

36. Latif, $\mathrm{A}$, Mongkolkeha, $\mathrm{C}$, Sintunavarat, W: Fixed point theorems for generalized $\alpha$ - $\beta$-weakly contraction mappings in metric spaces and applications. Sci. World J. 2014, Article ID 784207 (2014)

37. Kutbi, MA, Sintunavarat, W: Fixed point theorems for generalized $w_{\alpha}$-contraction multivalued mappings in $\alpha$-complete metric spaces. Fixed Point Theory Appl. 2014, 139 (2014)

38. Kutbi, MA, Sintunavarat, W: Fixed point analysis for multi-valued operators with graph approach by the generalized Hausdorff distance. Fixed Point Theory Appl. 2014, 142 (2014)

39. Bota, M, Karapınar, E, Mleşniţe, O: Ulam-Hyers stability results for fixed point problems via $\alpha$ - $\psi$-contractive mapping in (b)-metric space. Abstr. Appl. Anal. 2013, Article ID 825293 (2013)

40. Bakhtin, IA: The contraction mapping principle in quasimetric spaces. In: Functional Analysis, vol. 30, pp. 26-37. Ulyanowsk Gos. Ped. Inst., Ulyanowsk (1989)

41. Czerwik, S: Nonlinear set-valued contraction mappings in b-metric spaces. Atti Semin. Mat. Fis. Univ. Modena 46, 263-276 (1998)

42. Boriceanu, M, Bota, M, Petru, A: Multivalued fractals in b-metric spaces. Cent. Eur. J. Math. 8(2), 367-377 (2010)

43. Berinde, V: Generalized contractions in quasimetric spaces. In: Seminar on Fixed Point Theory. Preprint, vol. 3, pp. 3-9 (1993)

44. Berinde, V: Contracţii generalizate şi aplicaţii. Editura Club Press 22, Baia Mare (1997)

45. Berinde, V: Sequences of operators and fixed points in quasimetric spaces. Stud. Univ. Babeş-Bolyai, Math. 16(4), 23-27 (1996)

46. Berinde, V: Iterative Approximation of Fixed Points. Editura Efemeride, Baia Mare (2002)

doi:10.1186/1029-242X-2014-418

Cite this article as: Phiangsungnoen and Kumam: Generalized Ulam-Hyers stability and well-posedness for fixed

point equation via $\alpha$-admissibility. Journal of Inequalities and Applications 2014 2014:418. 